\title{
The Application of TOPSIS Method to Group Decision Making based on Similarity Measures under Interval-valued Intuitionistic Fuzzy Settings
}

\author{
Lishi Zhang \\ School of Science, Dalian Ocean University, Dalian, China \\ zls@dlou.edu.cn
}

\begin{abstract}
Keywords: Topsis method; Interval-valued fuzzy soft set; Attribute; Weights; Similarity measure; Group decision makings
\end{abstract}

\begin{abstract}
The aim of this paper is to develop a novel approach for multiple attributes group decision making, in which the decision information, provided by multiple decision makers, is presented in the form of interval-valued intuitionistic fuzzy numbers. First, the aggregated information matrix corresponding to all decision makers is calculated with the weights of both attributes and decision makers, the aggregated matrix is obtained. Then, a new biparametric similarity measure is used to computed the similarity between the alternatives and the positive ideal point and negative point via the idea of the TOPSIS of Hwang and Yoon (1981), the optimal choice is computed to choose the alternatives which perform best, an illustrative example is presented to demonstrate its effectiveness and validness of the proposed approach.
\end{abstract}

\section{Introduction}

The theory of intuitionistic fuzzy sets (IFSs), proposed the Atanassov [1], has drawn a great deal of attention for its flexibility to deal with fuzzy and imprecise information, the application of the multicriteria decision making (MCDM) methods have been carried out in [2-5] based on IFSs. In [2] , Chen et al propose two score functions for evaluating the suitability of an alternative across all criteria in an intuitionistic fuzzy environment. In [6], Li et al presented a MCDM approach by combining the quality function with the technique for order preference by similarity to an ideal solution (TOPSIS) method[7]under intuitionistic fuzzy environments. Pei and Zheng [8] present a new approach to multi-attribute decision making problems in intuitionistic fuzzy environment, in which the evaluated values (in the form of intervals) of the same alternative with different attributes are considered as one unified entity, Wang and Zhang [9]presented a MCDM method based on IFSs with incomplete certain information on weights.Wang and Liu[10] presented some intuitionistic fuzzy geometric aggregation operators based on Einstein operations for multiattribute decision making. Wu and Zhang[11] proposed a MCDM method based on intuitionistic weighted entropy measures. Wu and Chen[12] developed a multiattribute decision making method based on the ELECTRE method[13] and the TOPSIS method [7] ,Joshi and Kumar [14] proposed a MCDM method based on the TOPSIS method [7] ,distance measures and intuitionistic fuzzy entropy measures. Wang and Wei [15] developed a multiattribute decision making method for dealing with the supplier selection in the environment of supply chain management with intuitionistic fuzzy information, where the information about the weights of attributes is completely known and the values of the attributes are represented in form of intuitionistic fuzzy numbers. Wu and Chen[16] presented an intuitionistic fuzzy ELECTRE method for MCDM based on the ELECTRE method .

The rest of the manuscript is organized as follows. Section 2 briefly recalls some background knowledge about interval-valued intuitionistic fuzzy sets and TOPSIS method. Section 3 outline the proposed algorithms. Section 4 gives an illustrative example to testify our proposed methods and the comparison with the previous approach is made. 


\section{Preliminaries}

In this section, we will briefly recall some basic concepts and notions, background knowledge of interval valued intuitionistic fuzzy sets is introduced.

Definition 2.1.[18] Let $X$ a set, an interval valued intuitionistic fuzzy set (IVIFS) $A$ in $X$ is defined as

$A=\left\{\left\langle x, \mu_{A}(x), v_{A}(x)\right\rangle \mid x \in X\right\}$

Where $\mu_{A}(x)$ and $v_{A}(x)$ with the condition $0 \leq \sup \left(\mu_{A}(x)+v_{A}(x)\right) \leq 1$, the intervals $\mu_{A}(x)$ and $v_{A}(x)$ represent, respectively, the membership degree and nonmembership degree of the element $x$ to the set $A$. For each $x \in X$, and $\mu_{A}(x)$ and $v_{A}(x)$ are closed intervals and their lower and upper end points are, respectively, denoted by. $\mu_{A L}(x)$ and $\mu_{A U}(x), v_{A L}(x)$ and $v_{A U}(x)$.Thus, an IVIFS $A$ in $X$ is expressed by

$$
A=\left\{\left\langle x \mid\left[\mu_{A L}(x), \mu_{A U}(x)\right],\left[v_{A L}(x), v_{A U}(x)\right]\right\rangle \mid x \in X\right\}
$$

Where $0 \leq \mu_{A U}(x)+v_{A U}(x) \leq 1$,

Definition 2.2[19] Let $A, B$ be two IVIFVs in $X=\left\{x_{1}, x_{2}, \cdots, x_{n}\right\}$, the distance between $A$ and $B$ is

$$
D(A, B)=\sqrt[p]{\frac{1}{2 n(t+1)^{p}} \sum_{i=1}^{n}\left[\left(\mid t\left(\mu_{A}\left(x_{i}\right)-\mu_{B}\left(x_{i}\right)|+| v_{A}\left(x_{i}\right)-v_{B}\left(x_{i}\right) \mid p+\left(\mid t\left(v_{A}\left(x_{i}\right)-v_{B}\left(x_{i}\right)++\left|\mu_{A}\left(x_{i}\right)-\mu_{B}\left(x_{i}\right)\right| p\right.\right.\right.\right.\right.}
$$

\section{The Proposed Algorithms}

The following assumptions or notations are used to represent the MADM problems with known weight information in intuitionistic fuzzy setting. Let $A=\left\{A_{1}, A_{2}, \cdots, A_{m}\right\}$ be a set of alternatives, and $E=\left\{E_{1}, E_{2}, \cdots, E_{k}\right\}$ be a set of experts, and $C=\left\{C_{1}, C_{2}, \cdots, C_{n}\right\}$ be a set of attributes. where $w=\left(w_{1}, w_{2}, \cdots, w_{n}\right)^{T}$ is the weight vector of attributes with $w_{i} \in[0,1]$ and $\sum_{i=1}^{n} w_{i}=1$, where $\omega=\left(\omega_{1}, \omega_{2}, \cdots, \omega_{k}\right)^{T}$ is the weight vector of experts with $\omega_{i} \in[0,1]$ and $\sum_{i=1}^{K} \omega_{i}=1$, the information given by expert $k$ is

$$
R_{k}=\left(r_{i j}^{k}\right)_{n \times m}, r_{i j}^{k}=\left(\left[a_{i j}^{k}, b_{i j}^{k}\right],\left[c_{i j}^{k}, d_{i j}^{k}\right]\right)
$$

The average of the information matrix is

$$
R=\left(r_{i j}\right)_{n \times m}, r_{i j}=\frac{1}{k} \sum_{k=1}^{K} \omega_{i} \sum_{i=1}^{m} r_{i j}^{k}, r_{i}=\left(r_{i 1}, r_{i 2}, \ldots, r_{i n}\right)
$$

Let

$$
\begin{aligned}
& r^{+}=(\langle[1,1],[0,0]\rangle,\langle[1,1],[0,0]\rangle, \ldots,\langle[1,1],[0,0]\rangle), \\
& r^{-}=(\langle[0,0],[1,1]\rangle,\langle[0,0],[1,1]\rangle, \ldots,\langle[0,0],[1,1]\rangle)
\end{aligned}
$$

Be the positive ideal and negative ideal

Computed the distance measure of between all the alternatives and positive ideal and negative ideal,

$$
\begin{aligned}
& D\left(r_{i}, r^{+}\right) \text {and } D\left(r_{i}, r^{-}\right) \text {.The scores of } A_{i}(1 \leq i \leq m) \text { is } \\
& S\left(A_{i}\right)=D\left(r_{i}, r^{+}\right) /\left(D\left(r_{i}, r^{+}\right)+D\left(r_{i}, r^{-}\right)\right)
\end{aligned}
$$

By ranking the scores in descending order, we get optimal alternatives. 


\section{Case Study}

The 16th Asian Olympic Games will be held in Guangzhou during November 12 - 27, 2010. In what follows, we will present a comprehensive evaluation of the air quality in Guangzhou for the Novembers of 2006, 2007, 2008, and 2009 in order to forecast the air quality during the 16th Asian Olympic Games. The each air-quality monitoring station can be considered as a DM. For convenience, we select three air-quality monitoring stations, namely. The measured values are shown in $R_{1}, R_{2}, R_{3}$. The monthly air quality for the Novembers of 2006, 2007, 2008 and 2009, respectively, can be considered as alternatives. For convenience, let

$\mathrm{A}=\{\mathrm{A} 1, \mathrm{~A} 2, \mathrm{~A} 3, \mathrm{~A} 4\}=\{$ Novembers of 2006 , Novembers of 2007, Novembers of 2008, Novembers of 2009\}

$$
\mathrm{C}=\{\mathrm{C} 1, \mathrm{C} 2, \mathrm{C} 3\}=\{\mathrm{SO} 2, \mathrm{NO} 2, \mathrm{PM} 10\}, E=\left\{E_{1}, E_{2}, E_{3}\right\},
$$

The weight of attributes is $w=(0.3142,0.3549,0.3309)^{T}$, the weight of expers is $\omega=(0.4,0.2,0.4)^{T}$.

The information matrix presentation given by experts $E=\left\{E_{1}, E_{2}, E_{3}\right\}_{\text {is }} R_{1}, R_{2}, R_{3}$.

$$
\begin{array}{r}
R_{1}=\left[\begin{array}{lll}
A_{1}([0.22,0.31],[0.23,0.54]) & ([0.13,0.53],[0.20,0.36]) & ([0.12,0.37],[0.40,0.56]) \\
A_{1}([0.28,0.41],[0.33,0.49]) & ([0.33,0.53],[0.20,0.36]) & ([0.12,0.37],[0.30,0.46]) \\
A_{1}([0.32,0.41],[0.23,0.44]) & ([0.43,0.53],[0.16,0.25]) & ([0.23,0.45],[0.21,0.37]) \\
A_{1}([0.39,0.47],[0.18,0.36]) & ([0.39,0.53],[0.27,0.32]) & ([0.28,0.34],[0.11,0.23])
\end{array}\right] \\
R_{2}=\left[\begin{array}{lll}
A_{1}([0.04,0.21],[0.35,0.46]) & ([0.10,0.34],[0.27,0.45]) & ([0.32,0.37],[0.13,0.20]) \\
A_{2}([0.32,0.39],[0.27,0.39]) & ([0.03,0.57],[0.30,0.36]) & ([0.16,0.25],[0.14,0.19]) \\
A_{3}([0.26,0.37],[0.21,0.40]) & ([0.23,0.43],[0.06,0.15]) & ([0.21,0.35],[0.11,0.29]) \\
A_{4}([0.30,0.43],[0.19,0.35]) & ([0.28,0.43],[0.31,0.34]) & ([0.39,0.46],[0.01,0.17])
\end{array}\right] \\
R_{3}=\left[\begin{array}{lll}
A_{1}([0.25,0.27],[0.23,0.40]) & ([0.17,0.27],[0.26,0.40]) & ([0.21,0.30],[0.17,0.32]) \\
A_{2}([0.25,0.29],[0.33,0.39]) & ([0.18,0.46],[0.43,0.50]) & ([0.06,0.21],[0.28,0.30]) \\
A_{3}([0.22,0.27],[0.27,0.31]) & ([0.13,0.37],[0.16,0.20]) & ([0.11,0.24],[0.14,0.19]) \\
A_{4}([0.30,0.48],[0.09,0.45]) & ([0.08,0.53],[0.20,0.24]) & ([0.32,0.61],[0.01,0.09])
\end{array}\right]
\end{array}
$$

We get the aggregated matrix

$$
R=\left[\begin{array}{l}
A_{1}([0.0221,0.0348],[0.0363,0.0620]),([0.0088,0.0251],[0.0163,0.0270]),([0.0294,0.0462],[0.0304,0.0470]) \\
A_{2}([0.0379,0.0484],[0.0412,0.0562]),([0.0116,0.0347],[0.0208,0.0271]),([0.0152,0.0366],[0.0315,0.0415]) \\
A_{3}([0.0354,0.0466],[0.0315,0.0510]),([0.0173,0.0294],[0.0083,0.0132]),([0.0244,0.0460],[0.0202,0.0376]) \\
A_{4}([0.0438,0.0612],[0.0205,0.0515]),([0.0166,0.0330],[0.0174,0.0200]),([0.0443,0.0629],[0.0051,0.0217])
\end{array}\right]
$$

Furthermore, by computing, we get that

$$
{ }_{1} S\left(A_{1}\right)=0.4960, S\left(A_{2}\right)=0.4974, S\left(A_{3}\right)=0.5028, S\left(A_{4}\right)=0.5095
$$

The order of scores are listed as follows

$$
A_{4} \succ A_{3} \succ A_{2} \succ A_{1}
$$

The most desirable choose is Novembers of 2006. This result is in agreement with the one obtained in [19].

\section{References}

[1] Krassimir T. Atanassov, Intuitionistic fuzzy sets, Fuzzy Sets Syst.20(1986)87-96.

[2] L.H. Chen, C.C. Hung, C.C. Tu , Considering the decision maker's attitudinal character to solve multi-criteria decision making problems in an intuitionistic fuzzy environment, Know Based Syst. 36 (2012) 129-138 .

[3] S.M. Chen, S.H. Cheng, T.C. Lan, A new multicriteria decision making method based on the TOPSIS method and similarity measures between intuitionistic fuzzy values, in: Proceedings of 
2016 International Conference on Machine Learning and Cybernetics, Jeju Island, South Korea, China, 2016 .

[4] T.Y. Chen, Bivariate models of optimism and pessimism in multi-criteria decision-making based on intuitionistic fuzzy sets, Inf. Sci. 181 (11) (2011) 2139-2165.

[5] T.Y. Chen, A comparative analysis of score functions for multiple criteria decision making in intuitionistic fuzzy settings, Inf. Sci. 181 (17) (2011) 3652-3676 .

[6] M. Li , L. Jin , J. Wang, A new MCDM method combining QFD with TOPSIS for knowledge management system selection from the user's perspective in intuitionistic fuzzy environment, Appl. Soft Comput. 21 (2014) 28-37.

[7] Y.J. Lai, T.Y. Liu, C.L. Hwang, TOPSIS for MODM, Eur. J. Oper. Res. 76 (3) (1994) 486-500.

[8] Z. Pei, L. Zheng, A novel approach to multi-attribute decision making based on intuitionistic fuzzy sets, Expert Syst. Appl. 39 (3) (2012) 2560-2566

[9] J.Q.Wang, H.Y.Zhang, Multicriteria decision-making approach based on Atanassov's intuitionistic fuzzy sets with incomplete certain information on weights, IEEE Trans. Fuzzy Syst. 21 (3) (2013) $510-515$

[10] W.Wang, X. Liu, Intuitionistic fuzzy geometric aggregation operators based on Einstein operations, Int. J. Intell. Syst. 26 (11) (2011) 1049-1075

[11] J. Wu , Q. Zhang, Multicriteria decision making method based on Intuitionistic fuzzy weighted entropy, Expert Syst. Appl. 38 (1) (2011) 916-922

[12] M.C. Wu , T.Y. Chen , The ELECTRE multicriteria analysis approach based on intuitionistic fuzzy sets, in: Proceedings of the 2009 IEEE International Conference on Fuzzy Systems, Jeju Island, Korea, 2009, pp. 1383-1388

[13] R. Benayoun, B. Roy, B. Sussman, ELECTRE: Une me 'thode pour guider le choix en pre 'sence de points de vue multiples, Note de travail 49, SEMA- METRA International, Direction Scientifique, 1966.

[14]D. Joshi, S. Kumar , Intuitionistic fuzzy entropy and distance measure based on TOPSIS method for multi-criteria decision making, Egyptian Inform. J. 15 (2) (2014) 97-104.

[15] H. Wang, G. Wei, An effective supplier selection method with intuitionistic fuzzy information, in: Proceedings of the 2008 International Conference on Wireless Communications, Networking and Mobile Computing, Dalian, China, 2008, pp. 1-4 .

[16] M.C. Wu , T.Y. Chen ,The ELECTRE multicriteria analysis approach based on Atanassov's intuitionistic fuzzy sets, Expert Syst. Appl. 38 (10) (2011) 12318-12327 .

[17] K. T. Atanassov, More on intuitionistic fuzzy sets, Fuzzy Sets Syst, 33(1989)37-46.

[18] K.T.Atanassov, Operators over interval-valued intuitionistic fuzzy sets, Fuzzy Sets Syst, 64,(1994)159-174.

[19]E.B.Fatih , A biparametric similarity measure on intuitionistic fuzzy sets with applications to pattern recognition, Inf. Sci. 255 (2014) 45-57. 